www.jmscr.igmpublication.org

Impact Factor 5.84

Index Copernicus Value: 71.58

ISSN (e)-2347-176x ISSN (p) 2455-0450

crossref DOI: _https://dx.doi.org/10.18535/jmscr/v5i10.176

\author{
Journal Of Medical Science And Clinical Research \\ IGM Publication \\ An Official Publication of IGM Publication
}

\title{
Outcome of Pregnancy in Elderly Primigravida
}

\author{
Authors \\ Dr Vasanthakumari K $\mathbf{P}^{\mathbf{1}}$, Prof. Dr Nandini Vamdevan Retnamma ${ }^{2}$ \\ ${ }^{1}$ Associate Professor, Dept. of O and G, SAT hospital, Govt. Medical College, Trivandrum \\ ${ }^{2}$ Professor, Dept. of O and G, SAT hospital, Govt. Medical College, Trivandrum \\ Corresponding Author \\ Prof. Dr Nandini Vamdevan Retnamma \\ Professor, Dept. of O and G, SAT hospital, Govt. Medical College, Trivandrum
}

\begin{abstract}
Background: In India, the average age of marriage is 20-23 years and majority of women complete their families by the first half of their twenties. With improved health and education, increasing number of women in our state are postponing their first child. An elderly nulliparous woman is one who is aged 35 years or more. As age advances, there is a reduction in fertility. Women thirty five years or older have greater risk of diabetes, spontaneous abortions, hypertensive disorders, trisomies, caesarian births and maternal mortality. This study aims to measure the maternal complications, type of delivery, labor complications, fetal outcome in addition to socio-demographic factors.
\end{abstract}

Methods: This is a case control study. Elderly nulliparous women i.e. 35 years or above will be taken as case and those nulliparous women in the age group 20-29 years will be considered as control.

Results: Data collected are tabulated and analyzed using SPSS package.

150 nulliparous women in the age group of 35 years and above were taken as the study group and appropriately matched. 150 nulliparous women belonging to the age group of 20-29 were taken as control group. Both groups were identical with respect to religion. There was a threefold increased incidence of spontaneous abortions among study group as compared to control group. Among the study group, 24 percent underwent treatment for infertility where as only 5 percent in the control group had similar treatment. The incidence of antenatal complications were four times higher in the study group. The incidence of Caesarian section was 21 percent in the study group and 2 percent in the control group. Meconium stained liquor was 2 times higher in the study group. There was no difference in the incidence of postpartum complications in the two groups.

Conclusion

1. Previous spontaneous abortions were found to be three fold higher in the study group as compared to the control group.

2. Antenatal complications were four times higher in the study group as compared to the control group.

3. Incidence of preeclampsia was four fold higher in the study group as compared to the control group.

4. Incidence of anemia was three fold higher in the study group as compared to the control group.

5. Incidence of gestational diabetes was seven times higher in the study group as compared to the control group.

6. Incidence of elective Caesarian section was high in the study group (21\% vs 2\%).

7. Incidence of neonatal complications was two times higher in the study group as compared to the control group.

8. There was no difference in the incidence of postpartum complications in the two groups

Keywords: Elderly, Nulliparous, Preeclampsia, Gestational diabetes, Caesarian section, Abortions, Neonatal. 


\section{Introduction}

In the modern society, people live longer in association with an improved quality of life and health. The age of marriage is influenced by the society in which they are living. Levels of education, degree of literacy and role of women in society influence the reproductive process.

With improving health and education, increasing number of women in our state are postponing their first child in order to settle themselves.

As age advances, fertility tends to decrease. Certain diseases like pelvic inflammatory disease, endometriosis, fibroid uterus, anovulatory disorders and tubal pathology are on the rise.

Women over thirty five years of age have greater risks of diabetes, spontaneous abortions, hypertensive disorders, autosomal trisomy, maternal mortality and Caesarian births.

Majority of studies on the subject have stressed the decline of physiological activity and efficacy in this group of patients along with an increased incidence of maternal complications giving rise to a high foetal mortality.

\section{Aims \& Objectives}

1. To study and compare antenatal complications in nulliparous women thirty five years and older with nulliparous women of age 20-29 years.

2. To study and compare mode of onset of labor, mode of delivery and intrapartum and postpartum complications in the two groups.

\section{Materials \& Methods}

Design: Case control study. Elderly nullipara 35 years or older will be taken as case and nullipara in the age group 20-29 years will be considered as control

Setting: Department of Obstetrics and Gynecology, Government Medical College, Trivandrum

Inclusion Criteria: All elderly nullipara registering in the hospital during a 18 month period are considered cases. Nullipara aged 20-29 years recorded serially next in the obstetric register were taken as the control group.

Exclusion Criteria - Nil

\section{Outcome Measures}

Important outcome measures include maternal complications, type of delivery, labour complications, foetal outcome in addition to socio-demographic factors.

\section{Statistical Analysis}

Data entered into master sheet and analyzed using SPSS package.

\section{Results}

During the study period, 150 nulliparous women in the age group 35 years and above were taken as study group. Appropriately matched 150 nulliparous women belonging to the age group 2029 years were taken as control group. These cases were compared with regards to antenatal complications, onset of labor, mode of delivery, intrapartum complications, postpartum complications and neonatal outcome.

\section{Distribution According to Duration of Marital Life}

\begin{tabular}{|l|c|c|c|c|c|}
\hline \multirow{2}{*}{ Group } & \multicolumn{2}{|c|}{ Duration below 4 years } & \multicolumn{2}{|c|}{ Duration 4 yrs and above } & Total \\
\cline { 2 - 6 } & No & $\%$ & No & $\%$ & \\
\hline Study group & 103 & 69 & 47 & 31 & 150 \\
\hline Control group & 145 & 97 & 5 & 3 & 150 \\
\hline
\end{tabular}

31 percent of study group had 4 or more years of marital life while 3 percent of control group had a longer married life.

\begin{tabular}{l|l|c|c|c|c|c|}
\hline \multirow{3}{*}{ Group } & \multicolumn{4}{|c|}{ History of previous abortion } & \multirow{2}{*}{ Total } \\
\cline { 2 - 5 } & \multicolumn{3}{|c|}{ Present } & \multicolumn{2}{c|}{ Absent } & \\
\cline { 2 - 5 } & No & $\%$ & No & $\%$ & \\
\hline Study group & 36 & 24 & 114 & 76 & 150 \\
\hline Control group & 12 & 8 & 138 & 92 & 150 \\
\hline$p<0.001$
\end{tabular}


In the control group, history of abortion was present in 8 percent compared to 24 percent among women in the age group 35 years and above.

\section{Distribution According to Presence or Absence of Antenatal Complications}

\begin{tabular}{|c|c|c|c|c|c|}
\hline \multirow[t]{3}{*}{ Group } & \multicolumn{4}{|c|}{ History of previous abortion } & \multirow[t]{3}{*}{ Total } \\
\hline & \multicolumn{2}{|c|}{ Present } & \multicolumn{2}{|c|}{ Absent } & \\
\hline & No & $\%$ & No & $\%$ & \\
\hline Study group & 36 & 24 & 114 & 76 & 150 \\
\hline Control group & 12 & 8 & 138 & 92 & 150 \\
\hline
\end{tabular}

$$
p<0.001
$$

$51 \%$ of the 150 cases in the study group had antenatal complications whereas $13 \%$ in the control group had complications. Also the risk of antenatal complications were 4 times higher in women of the age group 35 years and above. This association was statistically significant. Preeclampsia was the major complication detected. $13 \%$ of women in the study group had preeclampsia

where as in the control group, it was only $3.3 \%$. The $\mathrm{Z}$ test for proportion showed the difference as highly significant. Gestational diabetes alone or along with gestational hypertension was present in $10 \%$ of the study group. This was only $1.3 \%$ in the control group. The incidence of fibroid complicating pregnancy was more than 2 times in the study group.

Anemia was identified in $11 \%$ of cases while it was only $3.3 \%$ in the control group.

\begin{tabular}{|l|c|c|c|c|c|c|}
\hline \multirow{2}{*}{ Maternal Disease } & Study group & Control Group & Z value & P Value & \multicolumn{2}{|c|}{} \\
\cline { 2 - 6 } & No & $\%$ & No & $\%$ & & \\
\hline Pre eclampsia & 20 & 13 & 5 & 3.3 & & $<.01$ \\
Mild & 10 & 50 & 2 & 40 & 3.1 & \\
Moderate & 6 & 30 & 2 & 40 & & \\
Severe & 4 & 20 & 1 & 20 & & \\
\hline Anemia & 16 & 11.0 & 5 & 3.3 & 3.49 & $<.01$ \\
\hline Gestational Diabetes mellitus & 15 & 10.0 & 2 & 1.3 & 2.90 & $<0.05$ \\
\hline Fibroid & 8 & 5.3 & 3 & 2.0 & 2.9 & $<0.05$ \\
\hline Jaundice & 2 & 1.3 & & & & \\
\hline Rheumatic heart disease & 2 & 1.3 & & & & \\
\hline Psychiatric illness & 2 & 1.3 & & & & \\
\hline Others & 8 & 5.3 & 2 & 1.3 & & \\
\hline
\end{tabular}

In the study group, $69 \%$ cases had a period of gestation of $37-40$ weeks at the time of termination compared to $55.3 \%$ in the control group. Three times increased risk of termination was present in the study group during 33-36 weeks of gestation compared to control group.

\begin{tabular}{|l|c|c|c|c|}
\hline \multirow{2}{*}{ Onset of labour } & \multicolumn{2}{|c|}{ Study group } & \multicolumn{2}{c|}{ Control group } \\
\cline { 2 - 5 } & No & $\%$ & No & $\%$ \\
\hline Spontaneous & 90 & 60 & 105 & 70 \\
\hline Induced & 28 & 19 & 42 & 28 \\
\hline Elective caesarean & 32 & 21 & 3 & 2 \\
\hline$p<0.001$
\end{tabular}

$21 \%$ in the study group had elective Caesarian section whereas in the control group it was only $2 \%$. 
Distribution According to Mode of Delivery

\begin{tabular}{|l|c|c|c|c|c|c|}
\hline \multirow{2}{*}{ Mode of Delivery } & \multicolumn{2}{|c|}{ Study group } & \multicolumn{2}{c|}{ Control Group } & $\begin{array}{c}\mathrm{Z} \\
\text { value }\end{array}$ & $\begin{array}{c}\text { P } \\
\text { Value }\end{array}$ \\
\cline { 2 - 5 } & No & $\%$ & No & $\%$ & & \\
\hline Vaginal & 50 & 33 & 114 & 76 & 8.2 & $<.001$ \\
\hline Spontaneous & 33 & 22 & 103 & 69 & 9.2 & $<.001$ \\
\hline Forceps & 2 & 1.3 & 1 & 0.7 & 0.6 & $>.05$ \\
\hline Vacuum & 15 & 10 & 10 & 6.7 & 1.04 & $>.05$ \\
\hline Cesarean & 100 & 66.6 & 36 & 24 & 12.1 & $<.001$ \\
\hline Elective & 32 & 21.3 & 3 & 2 & 5.5 & $<.01$ \\
\hline Emergency & 68 & 45.3 & 33 & 22 & 4.4 & $<.01$ \\
\hline
\end{tabular}

$76 \%$ of women in control group had vaginal delivery whereas it was only $33 \%$ in study group. Both elective as well as emergency Caesarian section were more in the study group. Vaginal delivery with forceps or vacuum did not show any appreciable differences.

\section{Indications for Elective Caesarian Section in the Study Group}

\begin{tabular}{|l|c|c|c|}
\hline & & No & $\%$ \\
\hline 1. & Elderly Primi, breech & 6 & 18.7 \\
\hline 2. & Elderly Primi, 1 st $^{\text {degree cephalo pelvic disproportion }}$ & 5 & 15.5 \\
\hline 3. & Elderly primi, pregnancy induced hypertension & 4 & 12.5 \\
\hline 4. & Elderly primi, gestational diabetes mellitus & 3 & 9.4 \\
\hline 5. & Elderly Primi, primi, placenta previa & 2 & 6.3 \\
\hline 6. & Elderly Primi, Placenta previa & 2 & 6.3 \\
\hline 7. & Bad obstetric history & 2 & 6.3 \\
& Pregnancy induced hypertension & & \\
\hline 8 & Bad Obstetric history & 6.3 \\
\hline 9. & Pregnnacy induced hypertension & 6 & 18.7 \\
\hline
\end{tabular}

In the control group, there were 150 live births whereas in the study group, there were 149 live births. There were two neonatal deaths and one intrauterine death in the study group but that was not found to be statistically significant.

\section{Distribution According to Birth Weight of Foetus}

\begin{tabular}{|l|c|c|c|c|}
\hline \multirow{2}{*}{ Birth weight } & \multicolumn{2}{|c|}{ Study group } & \multicolumn{2}{c|}{ Control group } \\
\cline { 2 - 5 } & No & $\%$ & No & $\%$ \\
\hline$<2.5 \mathrm{~kg}$ & 59 & 38.3 & 34 & 22.4 \\
\hline $2.5-3.4$ & 82 & 53.3 & 84 & 55.3 \\
\hline 3.5 and above & 13 & 8.4 & 34 & 22.3 \\
\hline
\end{tabular}

$77.6 \%$ of babies in control group had a weight of $2.5 \mathrm{~kg}$ or more whereas in the study group, only $61.7 \%$ had similar weight. This was found to be statistically significant with a $\mathrm{p}$ value of less than 0.001 .

\section{Discussion}

The elderly nulliparous women are at a higher risk for abortions, fibroids, preeclampsia, diabetes mellitus, operative interferences and low birth weight babies.
In the present study, $31 \%$ of the study group had a marital life of four years whereas it was only $3 \%$ in the control group. $42 \%$ conceived within one year of marriage. This differs from the study of elderly primigravida by R.T Booth et $\mathrm{al}^{1}$ (1961) which showed that one third of patients conceived within one year of marriage.

Studies by Jain A ${ }^{2}$ (1967), Guttmacher ${ }^{3}$ (1956), Vensey MP et $\mathrm{al}^{4}$ (1978), Schwartz et $\mathrm{al}^{5}$ (1982) demonstrated a marked decline in fertility of women aged above 35 years. 
In the study group, 51 percent had antenatal complications whereas only 13 percent had a similar problem in the control group. This shows that the risk of antenatal complications were about four times higher in women of the age group 35 and above. This is in accordance with the studies of Michael Prysak et al ${ }^{6}$ (1994), Kane $S^{7}$ (1967), Kirz D et al ${ }^{10}$ (1985), Nelson ${ }^{9}$ (1955).

13 percent in the study group had preeclampsia where as it was present in only 3.3\% in the control group. Studies by Kane $S^{7}$ (1967), Tysoe $F^{8}$ (1970), Kirz D et al ${ }^{10}$ (1985), Nelson ${ }^{9}$ (1955) also showed a higher incidence of hypertension among elderly nulliparous women.

In the study group, anemia was identified in 11 percent where as in the control group, it was only $3.3 \%$. in the study by McDonald and MacLennan ${ }^{11}$ (1960), there was a higher incidence of anemia in the young women $(2.7 \%)$ as compared to elderly primigravida $(1.7 \%)$.

Gestational diabetes mellitus either alone or with pregnancy induced hypertension was present in $10 \%$ of the study group. It was only $1.3 \%$ in the control group. These findings agree with previous studies by Kirz D et $\mathrm{al}^{10}$ (1985), Blum $\mathrm{M}^{12}$, Grimes D et al ${ }^{13}$ (1981).

The incidence of fibroid complicating pregnancy was more than two times higher in study group as compared to control group (5.3\% vs $2.9 \%$ ). The incidence of myomas in the study and control groups was higher when compared to previous studies by Michael Prysak et $\mathrm{al}^{6}$ (1994).

In the study group, 8 percent had their pregnancies terminated between 33-36 weeks compared to $2.7 \%$ in the control groups. This agrees with the previous studies by Tuck and Collaegues ${ }^{14}$ (1988) which showed a higher incidence of deliveries before 37 weeks in elderly nulliparous women.

21 percent in the study group had elective Caesarian section compared to 2 percent in the control group. Previous studies by J Mukherjee et $\mathrm{al}^{15}$ showed a higher incidence of Caesarian sections in elderly nulliparous women. Of those sectioned in labour, the section was performed in 50 percent for foetal distress; this being shown by the passage of meconium with or without changes in heart rate.

Regarding instrumental vaginal delivery, there was no appreciable difference between the two groups. Study by Booth et $\mathrm{al}^{1}(1961)$ showed that delivery with forceps rose from $10 \%$ in primigravida to $23 \%$ in the elderly primigravida.

38.3 percent of the study group had low birth weight compared to 22.4 percent in the control group, this finding agrees with that of Kane $S^{7}$ (1967) which shows a linear increase in low birth weight infants in primigravida over 35 years.

\section{Summary}

1) There was a threefold increased incidence of previous spontaneous abortions among study group compared to control group.

2) 31 percent of the study group had four or more years of marital life where as in control group, it was only 8 percent.

3) The incidence of antenatal complications were found to be four times higher in the study group as compared to the control group.

4) The incidence of preeclampsia was four times higher in the study group as compared to control group.

5) The incidence of anemia was three times higher in the study group as compared to the control group.

6) The incidence of elective Caesarian section was remarkably high in study group (21\% vs $2 \%)$.

7) There was no statistically significant difference in the incidence of intrauterine death or neonatal death in the study group as compared to the control group.

8) There was a strong negative correlation between age of the mother and baby weight.

\section{Conclusion}

Childbearing later in life is associated with a number of complications due to underlying chronic disorders. Most of these disorders are 
identifiable and can be successfully treated during pregnancy. Of utmost importance in all older women regardless of health status is an accurate assessment of the risk of fetal aneuploidy and its implications. Improved obstetric care has made advanced maternal age compatible with successful pregnancy for the great majority of such women.

\section{Bibliography}

1. R.T Booth and G.L Welhams: Elderly Primigravidae. Br.J.Obstet Gynaecol. 63: 249,1961

2. Jain A: Stochastic fertility models.An empirical test in Taiwan. Ann Arbor MI, University of Michigan 1967

3. Guttmacher AF: Factors affecting normal expectancy of conception. J.A.MA. 161:885-860,1956

4. Vessey M.P, Wright H: Fertility after stopping different methods of contraception. Br.Med.J.2:265,1978

5. Schwartz D, Mayaux MJ: Female fecunddity- Results of artificial insemination in 2193 nulliparous women with azoospermic husbands. N.Engl. J. Med.306:404,1982

6. Michael Prysak, Robert P Lorenz and Anne Kisly: Pregancy outcome in nulliparous women 35 years and older. Am.J.Obstet.Gynaecol.85:65,1994

7. Kane S: Advancing age and the primigravida.Obstet.Gynaecol.29:409,196 7

8. Tysoe F: Effect of age on the outcome of pregnancy. Trans .Pac. Coast. Obstet. Gynaecol. Loc38:8,1970

9. Nelson: Risk of hypertension as age advances. Br.J.Obstet Gynaecol. 23:169,1995

10. Kirz et al, Dorchester W and Freemani R: Advanced maternal age. The mature gravida. Am.J. Obstet. Gynaecol. 152:7,1985

11. Mac Donald IR and Mac Lennam HR: J.Obstet.Gynaec.Brit.Emp.67,443
12. Blum M: Is the elderly primigravida really at high risk: J.Perinatol.7:108,1979

13. Grimes D et al: Pregnancy outcomes in black women aged 35 and older. J.Obstet.Gynaecol.58:614,1981

14. Tuck SM, Yudkin PL, Turnbull AC: Pregnancy outcome in elderly primigravidae with and without a history of infertility. Br.J.Obstet. Gynaecol $.95: 230,1988$

15. J.Mukherjee, Roy Chowdhury: The Journal of Obstet. Gynaecol of India. 48:55,1998. 